F.W. Weckerly - Cave cricket exit counts: environmental influences and duration of surveys. Journal of Cave and Karst Studies, v. 74, no. 1, p. 1-6. DOI: $10.4311 / 2011$ LSC0223

\title{
CAVE CRICKET EXIT COUNTS: ENVIRONMENTAL INFLUENCES AND DURATION OF SURVEYS
}

\author{
Floyd W. WeCKeRlY ${ }^{1}$ \\ ${ }^{1}$ Department of Biology, Texas State University - San Marcos, San Marcos, Texas, 78666, USA, fw11@txstate.edu
}

\begin{abstract}
Cave cricket abundance is used as an indicator of integrity of cave ecosystems. One means of monitoring cave cricket abundance is counting crickets as they emerge from cave entrances for two hours after sunset. The influence of cloud cover, relative humidity, and surface temperature on counts is unknown and there might be few cave crickets that emerge during the first hour of the survey. Using mixed effects models, I assessed the influence of these environmental variables on exit counts and estimated when cave crickets emerged within the two-hour survey period. Exit-count surveys were conducted in eleven caves over four years in central Texas, and caves were surveyed up to four times a year across the four calendar seasons. Cloud cover, relative humidity, and temperature influenced counts, but the greatest influence was from temperature. Peaks in cave cricket counts occurred 80 to 90 minutes after the start of a survey and declined thereafter. Cave cricket exit count surveys should record surface temperature, cloud cover, and relative humidity at the start of surveys so that counts can be adjusted for these environmental influences. Also, surveys can be shortened to 1 or 1.5 hours in length.
\end{abstract}

\section{INTRODUCTION}

Cave crickets (Ceuthophilus) are often keystone species in cave ecosystems (Fagan et al., 2007; Lavoie et al., 2007; Taylor et al., 2007b). These insects provide inputs of allochthonous resources to caves that are often energy depauperate, the guano from cave crickets sustains invertebrate communities, and there are predators that specialize on the eggs laid by cave crickets (Taylor et al., 2005). Due to the inordinate influence of cave crickets on cave ecosystems, the number of cave crickets (hereafter abundance) that emerge from and return to caves is integral to the conservation of troglobitic endangered species and species of concern (Taylor et al., 2007b).

One means of monitoring abundance and temporal trends in cave crickets is with exit-count surveys (Taylor, et al., 2007b). Beginning at sunset on evenings when the surface temperature is at least $5{ }^{\circ} \mathrm{C}$, two surveyors count cave crickets for two hours as they emerge from a cave entrance. Environmental conditions that might influence cave cricket emergence are the amount of moonlight and the temperature and relative humidity on the surface (Campbell, 1976; Poulson et al., 1995; Yoder et al., 2011). Surface activity of cave crickets is reported to be lower when there is more moonlight, during cool or hot nighttime temperatures, and when relative humidity is lower. But how these environmental variables actually affect the number of cave crickets that emerge from caves has not been examined. Furthermore, cave crickets are rarely active and foraging on the surface during daylight hours (Campbell, 1976; Yoder et al., 2011). In Carlsbad Caverns National Park, Campbell (1976) noted that as many as $50 \%$ of the cave crickets that emerged on summer nights did so between one and two hours after sunset. Because cave cricket emergence occurs after sunset, the necessity of conducting counts beginning at sunset is questionable. Perhaps surveys should begin a half hour to one hour after sunset, when most cave crickets emerge. Also, if most cave crickets emerge one to two hours after sunset, need these surveys be conducted for two hours?

The ability of a survey technique to estimate populations is based on the accuracy of actual population estimates in the settings where the survey technique will be applied. Estimates obtained from surveys must be compared to known populations (e.g., Weckerly and Foster, 2010). For cave crickets, it would be quite challenging to know the actual population in caves, and thus, conduct a robust evaluation of the reliability of exit counts. Nevertheless, understanding what influences counts and when to survey, so that counts are conducted when animals are most likely to emerge, can be used to ensure that surveys are standardized. If counts are conducted when most animals emerge, then counts obtained may provide reliable information on cave cricket abundance.

The specific objectives of this study were to determine if and how cloud cover, relative humidity, and temperature influence exit-survey counts, to determine the magnitude of the influence of these environmental variables on counts, and to estimate when cave crickets emerged from cave entrances within the 2-hour survey period.

\section{SURVEYS}

Cave cricket exit-count surveys were conducted at eleven small caves in the Balcones Canyonlands Preserve, 
Table 1. Features and number of cave cricket exit count surveys conducted from $2006-2010$ on the Balcones Canyonlands Preserve, Travis County, Texas. Also, the number of surveys with adequate counts $(\geq 20)$ for analyses of survey length is reported. A dashed line denotes there were no surveys with data.

\begin{tabular}{lcccc}
\hline Cave & Length, $\mathrm{m}$ & Depth, m & No. of surveys & $\begin{array}{c}\text { No. of surveys for } \\
\text { analysis of survey length }\end{array}$ \\
\hline Amber & 10.2 & 7.5 & 10 & 8 \\
Cotterell & 7.9 & 7.6 & 11 & 11 \\
District Park & 74.7 & 13.4 & 11 & 11 \\
Flint Ridge & 283.0 & 46.5 & 11 & 11 \\
Gallifer & 35.0 & 7.4 & 11 & 10 \\
Kretschmarr & 7.6 & 11.4 & 13 & 12 \\
Kretschmarr DP & 8.0 & 4.3 & 6 & 7 \\
Root complex & 15.7 & 7.4 & 12 & 12 \\
Spider & 9.0 & 6.3 & 7 & $\ldots$ \\
Tardus & 6.0 & 5.6 & 9 & 6 \\
Tooth & 50.5 & & & $\ldots$ \\
\hline
\end{tabular}

Travis County, Texas, USA (Table 1). The Balcones Canyonlands Preserve is a discontinuous collection of properties consisting of 5,365 ha managed for endangered species. The surface environment is a mix of ashe juniper (Juniperus ashei), hardwoods (mostly oaks, Quercus spp.), shrublands, and grasslands with gently sloping to steepsided canyons. Daytime temperatures are hot (often $>$ $35{ }^{\circ} \mathrm{C}$ ) in summer and mild $\left(5\right.$ to $\left.25^{\circ} \mathrm{C}\right)$ in winter (Watson et al., 2008).

Exit-count surveys were conducted from 2006 to 2010. A survey consisted of two surveyors counting all cave crickets (juveniles, nymphs, and adults) that emerged from a cave opening in a 2-hour period that began at sunset. Red lights were used during surveys to aid in seeing cave crickets and reduce disturbing them. Species of cave crickets were Ceuthophilus secretus, sometimes C. cunicularis, and a species of Ceuthophilus yet to be described (species B, Taylor et al., 2007a). At the beginning of the surveys, the percentage of cloud cover (a visual estimate), the relative humidity, and the temperature were recorded. Percentage cloud cover was a practical way to account for some of the variation in light from the moon and stars. Count surveys were conducted in all four calendar seasons of the year. At each cave six to twelve surveys were conducted.

\section{AnALysis-EnVIRONMENTAL InFLUENCES}

I analyzed data using mixed-effects models because exitcount surveys were repeatedly conducted at each cave across the four years (Pinheiro and Bates, 2000). Because the response variable was a count, I used a generalized linear mixed-effects model assuming a Poisson distribution (Faraway, 2006).

Fixed factors (hereafter, variables) were cloud cover, temperature, and relative humidity. Variables that potentially influenced the response, counts of emerging cave crickets. Because surface activity of cave crickets should increase from cool to warm temperatures but decline with hot temperatures, I estimated a quadratic relationship between temperature and counts (Poulson et al., 1995). Cloud cover, relative humidity, and temperature were continuous variables (Sokal and Rohlf, 1995). Mixed-effect models can suffer from computational instability. The iterative algorithms and optimization programs that estimate parameters may not converge, parameters are estimated but confidence intervals are not, or the estimated confidence intervals are very wide (Pinheiro and Bates, 2000). To reduce the possibility of computational instability, I centered continuous variables (Cheng et al., 2010) by subtracting the values from the means. $z$-tests of coefficients of variables were used to assess if a variable had an influence on counts (Faraway, 2006).

To assess the magnitude of influence (MI) of cloud cover, relative humidity, and temperature, I calculated $\left|Y_{\max }-Y_{\min }\right| /\left|X_{\max }-X_{\min }\right|$, where the largest predicted count and its $X$ value were $Y_{\max }$ and $X_{\max }$ and the smallest predicted count and its $X$ value were $Y_{\min }$ and $X_{\min }$. A MI with a large value indicates that the variable had a large influence on counts. I calculated an MI in this manner because it is not possible to assess the magnitude of influence of variables by coefficients or $z$-tests when the units of predictors are not the same (Sokal and Rohlf, 1995).

Cave was treated as a random factor. Random factors were part of random effects, variances that allow relationships between fixed variables and the response variable to change among caves (Cheng et al., 2010). In the generalized linear mixed-effect model, there was one random effect, the cave. This allowed intercepts of the regressions between variables and counts to vary among the caves (Cheng et al., 2010).

To gauge the variability in the relationships between variables and counts, I estimated an intra-class correlation 
Table 2. Quartiles (first-25 $5^{\text {th }}$ percentile, second-median or $50^{\text {th }}$ percentile, third-75 ${ }^{\text {th }}$ percentile), minimum, and maximum values of percent cloud cover, percent relative humidity, temperature in Celsius, and counts during the 108 cave cricket exit count surveys conducted in $\mathbf{1 1}$ caves on the Balcones Canyonlands Preserve, Travis County, Texas.

\begin{tabular}{lcccc}
\hline Percentile & Count & Cloud Cover & Relative Humidity & Temperature \\
\hline Minimum & 1 & 0 & 16 & 7 \\
First quartile & 29 & 0 & 50 & 18 \\
Median & 149 & 20 & 60 & 24 \\
Third quartile & 258 & 42 & 75 & 28 \\
Maximum & 1536 & 100 & 98 & 34 \\
\hline
\end{tabular}

coefficient. The coefficient is calculated by dividing the variance of the intercept random effect by the sum of the residual and intercept variances (Pinheiro and Bates, 2000). The residual variance measures the squared deviation between observed and predicted response variables, just like in an ordinary least-squares regression. The quantity can range from 0 to 1 , with 0 indicating no variability in relationships across caves and 1 denoting tremendous variation in relationships across caves.

\section{Analysis-Two Hour Survey Period}

Mixed-effects models were also used to estimate emergence of cave crickets in the 2-hour survey period. However, because the response variable was continuous, I used linear mixed effects models. The response variable was the count during a 10-minute interval divided by the 2 -hour total and expressed as a percentage. I labeled the response variable percent count. Fixed variables were time, cloud cover, temperature, and relative humidity. Minutes was a discrete variable, coded 1 to 12 to reflect the twelve 10minute increments in the 2-hour survey period. The continuous variables of cloud cover, temperature, and relative humidity were centered. Minutes were modeled as a cubic relationship with percent counts; minutes had linear (minutes), quadratic (minutes ${ }^{2}$ ), and cubic (minutes $^{3}$ ) coefficients. A cubic relationship allowed for the possibility of a low percent count early in the two hour survey period and a peak and a decline in counts, if they existed, at the end of the survey period. Because I used a linear mixedeffects model, I conducted an analysis of variance to assess which variables were influencing percent count (not possible with a generalized linear mixed-effects model).
In this analysis I modeled random effects so that relationships of fixed variables could vary in intercepts, minutes, and minutes ${ }^{2}$. Because of the number of random effects, Pearson's correlation coefficients were also estimated to account for possible covariance between random effects. The linear mixed-effects model had correlation coefficients between intercepts and minutes, intercepts and minutes $^{2}$, and minutes and minutes ${ }^{2}$ (Pinheiro and Bates, 2000). Correlation coefficients estimated between random effects can have wide confidence intervals, indicative of computational instability (Pinheiro and Bates, 2000). In case this occurred, I modeled the random effects assuming there were no correlations (i.e., $r=0.0$ ). A preliminary examination of the data indicated the assumption of homoscedasticity was violated. Therefore, a variance function to characterize heteroscedasticity was used (Pinheiro and Bates, 2000). The variance function allowed residual variance to increase with increasing values of minutes.

\section{Findings-ENVIRONMENTAL INFLUENCES}

There were 108 exit-count surveys conducted in the eleven caves (Table 1). Across these surveys, counts ranged from 1 to 1536 (Table 2). The cloud cover during surveys ranged from open sky (no cloud cover) to complete cloud cover, with a median cloud cover of 20 percent. Relative humidity ranged widely, but half the surveys were conducted when relative humidity was between 50 and 75 percent. The first and third quartiles of temperatures at the start of surveys were $18{ }^{\circ} \mathrm{C}$ and $28{ }^{\circ} \mathrm{C}$, respectively.

There was a quadratic relationship between temperature and counts (Table 3). Cloud cover and relative

Table 3. Coefficients, standard errors, and findings from $z$-tests ( $z$ value, $P$ value) for fixed variables and intercept for the generalized, linear mixed effects model. Temperature and temperature ${ }^{2}$ estimated a quadratic relationship.

\begin{tabular}{lcccc}
\hline Coefficient & Value & SE & $z$ & $P$ \\
\hline Intercept & 5.169 & 0.2465 & 20.97 & $<0.001$ \\
Cloud cover & 0.003 & 0.0002 & 18.10 & $<0.001$ \\
Relative humidity & 0.002 & 0.0004 & -8.96 & $<0.001$ \\
Temperature $_{\text {Temperature }}^{2}$ & 0.021 & 0.0011 & 20.35 & $<0.001$ \\
\hline
\end{tabular}



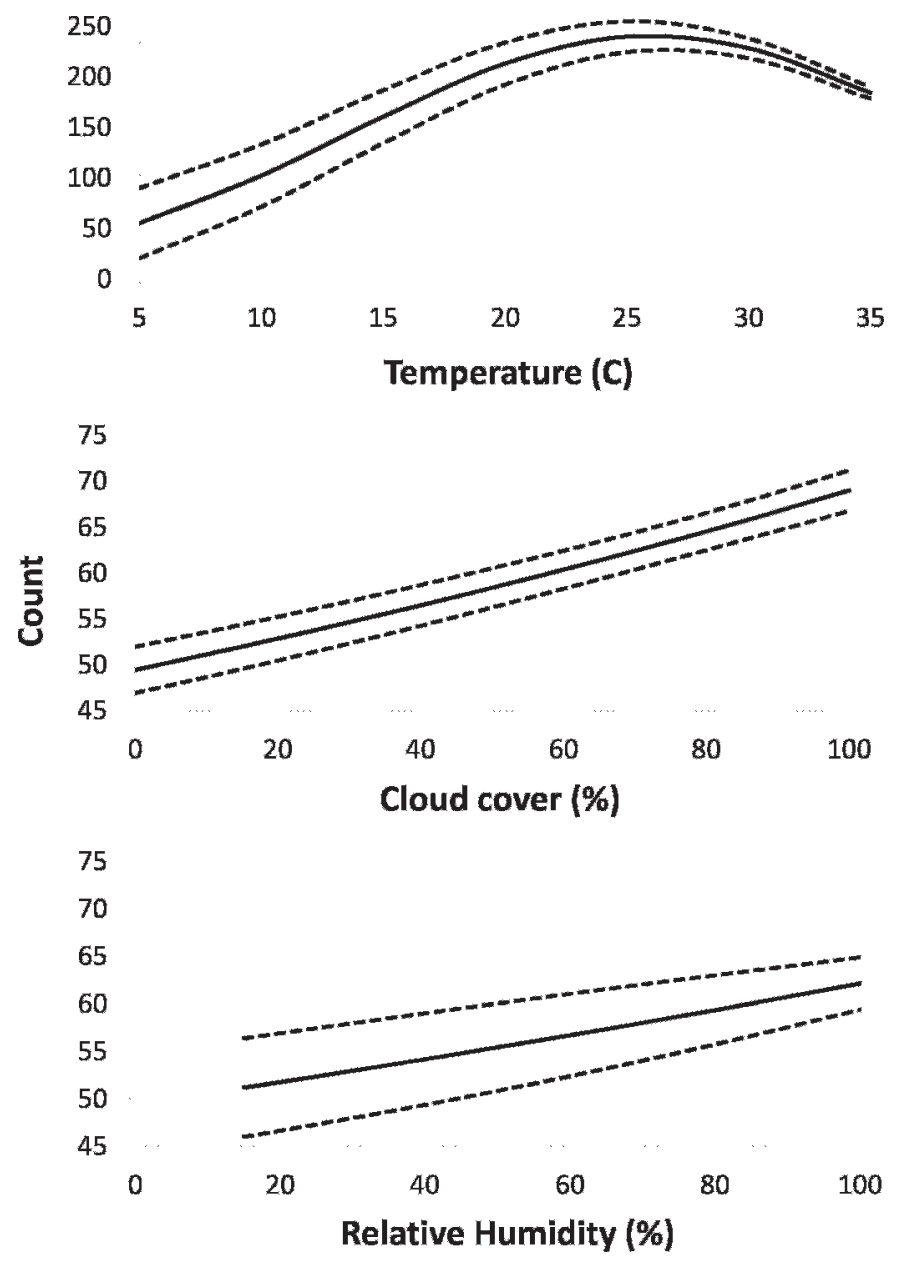

Figure 1. Graphs showing relationships (and 1 standard error envelopes) between relative humidity, cloud cover, temperature, and counts. Note that the scale for counts on the $Y$ axis differs between the temperature graph and the other two graphs.

humidity also influenced counts. Counts increased from cool temperatures $\left(5-10{ }^{\circ} \mathrm{C}\right)$ to warm temperatures $(\sim 25$ ${ }^{\circ} \mathrm{C}$ ) and declined with hotter temperatures (Fig. 1). Both cloud cover and relative humidity had positive relationships with counts.

To estimate the MI for temperature, I multiplied regression coefficients for cloud cover and relative humidity by their respective means. To estimate MI for cloud cover and relative humidity, I likewise multiplied the other coefficients by their means. The MI for temperature, cloud cover, and relative humidity were 9.2, 0.20, and 0.13 , respectively.

The residual variance for the generalized linear mixedeffects model was 0.76, and the intra-class correlation coefficient was 0.43 . The relationships of cloud cover, relative humidity, and temperature with cave cricket exit counts did vary across caves, but the differences were not dramatic.

\section{INTERPRETATION-ENVIRONMENTAL INFLUENCES}

All three environmental variables influenced counts of cave crickets emerging from caves. But temperature clearly had a much greater influence on counts than did cloud cover or relative humidity. The MI for temperature indicated that counts increased over 900 percent for every one degree increase in temperature between 5 and 25 (i.e., counts increased, on average, by nine cave crickets for every one degree increase in temperature), whereas cloud cover and relative humidity increased by only 13 to 20 percent for every one percent increase in these variables. The influence of temperature on counts, however, was not a straightforward linear increase. According to my analysis, cave crickets are most active in the Balcones Canyonlands Preserve when nighttime surface temperatures are between 20 and $30{ }^{\circ} \mathrm{C}$. The reduction in cave cricket emergence on cool and hot nights is consistent with studies indicating hot temperatures are stressful for cave crickets and that cave cricket activity is curtailed when surface temperatures are cool (Poulson et al., 1995; Studier and Lavoie, 1990).

Another finding from the analysis was that relationships between environmental influences on counts varied somewhat across caves. The relationships varied in intercepts but not in slopes. Therefore, the form of relationships did not change across caves. For example, the quadratic relationship between temperature and counts was the same from cave to cave. The variability in intercepts across caves suggests that caves varied in cave cricket abundance.

\section{Findings-Survey Length}

For the analysis of percent counts I only used surveys where a minimum of twenty cave crickets were counted, consequently there was data from nine caves and 88 exitcount surveys (Table 1). In the initial model there were no influences on percent count from temperature, relative humidity, or cloud cover $\left(F_{1,1038}<1.32, p>0.179\right)$. Another model (labeled full random effects in Table 4) was analyzed with these variables removed. The variables in the full random effects model were minutes, minutes ${ }^{2}$, and minutes $^{3}$. The full random effects model had issues with computational instability. Two of the three correlation coefficients had enormously wide confidence intervals, and I was not confident that this model estimated these parameters reliably. Thus, I ran the final model (subsets random effects in Table 4) without the correlation coefficients between all pairs of random effects (Table 4). Confidence bounds on estimates of all parameters (coefficients) and random effects of the subsets random effects model indicated that computational instability was less of a problem. The three coefficients for minutes (linear, quadratic, cubic) were useful to modeling the relationship between minutes and percent count because every confidence 
Table 4. Estimates and 95 percent lower and upper bounds of fixed and random effects of the mixed effects models that estimated relationship between minutes after start of cave cricket exit count survey (minutes) and the percentage of all cave crickets that were counted in $\mathbf{1 0}$ minute increments. The full random effects model included all correlations between random components. Because the correlation estimates had wide confidence intervals a subsets random effects model was estimated without correlation estimates. Minutes ${ }^{2}$ is a quadratic coefficient and minutes ${ }^{3}$ is a cubic coefficient. Standard deviation is denoted by $\mathbf{S}$ and $\mathbf{R}$ denotes Pearson's correlation coefficient.

\begin{tabular}{|c|c|c|c|c|c|c|c|}
\hline $\begin{array}{l}\text { Fixed } \\
\text { Parameter }\end{array}$ & $\begin{array}{l}\text { Lower } \\
\text { Bound }\end{array}$ & Coefficient & $\begin{array}{l}\text { Upper } \\
\text { Bound }\end{array}$ & $\begin{array}{c}\text { Random } \\
\text { Effect }\end{array}$ & $\begin{array}{l}\text { Lower } \\
\text { Bound }\end{array}$ & Estimate & $\begin{array}{l}\text { Upper } \\
\text { Bound }\end{array}$ \\
\hline \multicolumn{8}{|c|}{ Full Random Effects } \\
\hline Intercept & 9.03 & 10.69 & 12.36 & S(residual) & 2.34 & 2.66 & 3.01 \\
\hline Minutes & 0.81 & 1.42 & 2.04 & S(intercept) & 1.39 & 2.38 & 4.08 \\
\hline Minutes $^{2}$ & -0.33 & -0.20 & -0.06 & $\mathrm{~S}$ (minutes) & 0.51 & 0.85 & 1.43 \\
\hline Minutes $^{3}$ & -0.03 & -0.02 & -0.01 & S(minutes $\left.{ }^{2}\right)$ & 0.12 & 0.20 & 0.33 \\
\hline$\ldots$ & $\ldots$ & $\ldots$ & $\ldots$ & $\mathrm{R}$ (intercept, minutes) & -0.99 & -0.94 & 0.90 \\
\hline$\ldots$ & $\ldots$ & $\ldots$ & $\ldots$ & $\mathrm{R}$ (intercept, minutes $\left.{ }^{2}\right)$ & -1.00 & -0.99 & 0.73 \\
\hline$\ldots$ & $\ldots$ & $\ldots$ & $\ldots$ & $\mathrm{R}$ (minutes, minutes ${ }^{2}$ ) & 0.47 & 0.94 & 0.99 \\
\hline$\ldots$ & $\ldots$ & $\ldots$ & $\ldots$ & Variance function & 0.40 & 0.47 & 0.54 \\
\hline \multicolumn{8}{|c|}{ Subsets Random Effects } \\
\hline Intercept & 9.20 & 10.73 & 12.25 & S(residual) & 2.41 & 2.74 & 3.10 \\
\hline Minutes & 0.81 & 1.41 & 2.02 & S(intercept) & 1.23 & 2.15 & 3.76 \\
\hline Minutes $^{2}$ & -0.32 & -0.20 & -0.08 & S(minutes) & 0.51 & 0.83 & 1.36 \\
\hline \multirow[t]{2}{*}{ Minutes $^{3}$} & -0.03 & -0.02 & -0.01 & $\mathrm{~S}\left(\right.$ minutes $\left.^{2}\right)$ & 0.11 & 0.18 & 0.30 \\
\hline & & & & Variance function & 0.38 & 0.45 & 0.52 \\
\hline
\end{tabular}

interval did not overlap zero. Also, it was a good idea to model the heteroscedasticity as increasing residual standard deviation with increasing percent counts because the variance function had confidence intervals that did not overlap zero. The intra-class correlation coefficient was 0.38 for the subsets random effects model. The cubic

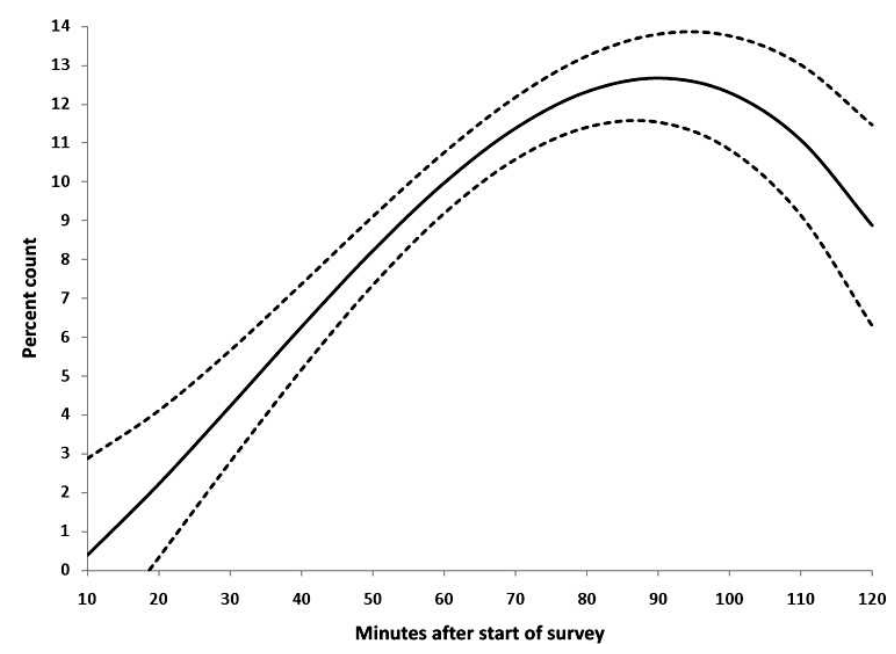

Figure 2. The relationship, and 1 standard error envelope, between minutes after the start of a cave cricket exit-count survey and the percentage of all cave crickets that were counted in the preceding 10-minute interval. relationship between minutes and percent count did vary among caves, but the variation was modest.

The peak in counts occurred between 80 and 90 minutes into the exit-count surveys (Figure 2). Counts increased dramatically from the beginning of the survey to the time of the peak and declined thereafter. I used the predicted percent count at each 10-minute increment to calculate the cumulative percent count. During the last 1.5 hours of a survey, 93 percent of all cave crickets were counted, and during the last 1.0 hours of a count survey, 69 percent of all cave crickets were counted.

The decline in percent counts in the last half hour of surveys indicates that extending surveys beyond 2 hours after sunset will not result in continued high counts, a finding that is consistent with emergence patterns of cave crickets in Carlsbad Caverns National Park (Campbell, 1976). Most crickets in that study emerged one to two hours after sunset. It was not surprising that cloud cover, relative humidity, and temperature did not influence time history of the counts but did influence total counts.

\section{CONCLUSIONS}

Proactive conservation of endangered species and species of concern in cave ecosystems requires monitoring of species that indicate the integrity of the cave ecosystem (Lavoie et al., 2007; Taylor et al., 2007b). In central Texas, Ceuthophilus cave crickets are the indicator species of cave productivity in the karst environment (Taylor et al., 
2007a). Information gathered from monitoring cave cricket abundance is used to estimate changes over time in the number of cave crickets that emerge from cave entrances, determine the state of cave ecosystems, assess whether goals of a conservation program are met, and implement actions to mitigate degradation of the cave environment. Fundamental to monitoring cave ecosystems is the protocol used to collect data on cave cricket abundance. A standardized survey protocol is merely a set of instructions that dictate that sufficient data are collected that analyses of the data can be done with statistical methods that can account for peculiarities in the data and heterogeneity in environmental conditions that influence cave cricket emergence. Standardization in how the data is collected is fundamental to assessing trends across time, a feature already present in cave cricket exit-count surveys. A feature of these data was that count surveys were conducted periodically across time in the same caves, which required the use of mixed-effects models that can accommodate the grouping of data by caves (Pinheiro and Bates, 2000). It is clear that heterogeneity in counts can be due to temperature, cloud cover, and relative humidity. Of these environmental influences temperature has the greatest influence on cave cricket emergence. To accommodate environmental heterogeneity in surveys there are two options. The first is to restrict surveys to when environmental conditions are most amenable to emergence. A drawback to this option is it will constrain the times when surveys can be conducted. The findings of my analysis suggest that, at the very least, surveys should be conducted when surface temperatures are between 20 and $30{ }^{\circ} \mathrm{C}$. The other option is to retain the existing protocol. By recording temperature, cloud cover, and relative humidity at the start of the survey, the influence of these variables on exit counts can be accounted for in analyses to detect temporal or spatial trends in cave cricket abundance.

In cave cricket exit-count surveys, one aspect of the required survey effort is the length of time to conduct survey. (The other is conducting counts at cave entrances when cave crickets emerge.) Because of logistical and monetary constraints, monitoring programs rarely enumerate the entire targeted population. Instead, a subset of the targeted population is counted. If the count is to reflect the actual population state, surveys should be conducted when individuals in the population are most readily counted. For surveys on the Balcones Canyonlands Preserve, that window of time appears to be 1 to 1.5 hours beginning a half hour to one hour after sunset.

\section{AcKnowledgements}

I thank Jason Hunt for collating the data and conducting the initial analyses. Ben Tobin generously provided literature, and Benjamin Schwartz read an earlier draft and offered many good suggestions. I also thank the many biologists and staff with the city of Austin and Travis County Texas for collecting the data and their assistance and feedback. The project was funded by the city of Austin.

\section{REFERENCES}

Campbell, G.D., 1976, Activity rhythm in the cave cricket, Ceuthophilus conicaudus Hubbell: American Midland Naturalist, v. 96, p. 350-366.

Cheng, J., Edwards, L.J., Maldonado-Molina, M.M., Komro, K.A., and Muller, K.E., 2010, Real longitudinal data analysis for real people: building a good enough mixed model: Statistics in Medicine, v. 29, p. 504-520. doi:10.1002/sim.3775.

Fagan, W.F., Lutscher, F., and Schneider, K., 2007, Population and community consequences of spatial subsidies derived from centralplace foraging: The American Naturalist, v. 170, p. 902-915. doi: $10.1086 / 522836$.

Faraway, J.J., 2006, Extending the Linear Model with R: Generalized Linear, Mixed Effects and Nonparametric Regression Models, New York, Chapman \& Hall, CRC Texts in Statistical Science, 312 p.

Lavoie, K.H., Helf, K.L., and Poulson, T.L., 2007, The biology and ecology of North American cave crickets: Journal of Cave and Karst Studies, v. 69, p. 114-134.

Pinheiro, J.C., and Bates, D.M., 2000, Mixed-Effects Models in S and SPLUS, New York, Springer Verlag, 548 p.

Poulson, T.L., Lavoie, K.H., and Helf, K.L., 1995, Long-term effects of weather on the cricket (Hadenoecus subterraneus, Orthoptera, Rhaphidophoridae) guano community in Mammoth Cave National Park: American Midland Naturalist, v. 134, p. 226-236.

Sokal, R.R., and Rohlf, F.J., 1995, Biometry: The Principles and Practice of Statistics in Biological Research, 3rd edition, New York, W.H. Freeman and Company, $887 \mathrm{p}$.

Studier, E.H., and Lavoie, K.H., 1990, Biology of cave crickets, Hadenoecus subterraneus, and camel crickets, Ceuthophilus stygius (Insecta: Orthoptera): metabolism and water economies related to size and temperature: Comparative Biochemistry and Physiology, Part A, v. 95, p. 157-161. doi:10.1016/0300-9629(90)90025-N.

Taylor, S.J., Krejca, J.K., and Denight, M.L., 2005, Foraging range and habitat use of Ceuthophilus secretus (Orthoptera: Phaphidophoridae), a key trogloxene in central Texas cave communities: American Midland Naturalist, v. 154, p. 97-114. doi:10.1674/0003-0031(2005) 154[0097:FRAHUO]2.0.CO;2.

Taylor, S.J., Krejca, J.K., and Hackley, K.C., 2007a, Examining Possible Foraging Differences in Urban and Rural Cave Cricket Populations: Carbon and Nitrogen Isotope Ratios $\left(\delta^{13} \mathrm{C}, \delta^{15} \mathrm{~N}\right)$ as Indicators of Trophic Level: Illinois Natural History Survey Technical Report 2007(59), 97 p.

Taylor, S.J., Weckstein, J.D., Takiya, D.M., Krejca, J.K., Murdoch, J.D., Veni, G., Johnson, K.P., and Reddell, J.R., 2007b, Phylogeography of Cave Crickets (Ceuthophilus spp.) in Central Texas: A Keystone Taxon for the Conservation and Management of Federally Listed Endangered Cave Arthropods: Illinois Natural History Survey Technical Report 2007(58), 45 p.

Watson, C.A., Weckerly, F.W., Hatfield, J.S., Farquhar, C.C., and Williamson, P.S., 2008, Presence-nonpresence surveys of goldencheeked warblers: detection, occupancy and survey effort: Animal Conservation, v. 11, p. 484 492. doi:10.1111/j.1469-1795.2008.00204.x.

Weckerly, F.W., and Foster, J.A., 2010, Blind count surveys of whitetailed deer and population estimates using Bowden's estimators: Journal of Wildlife Management, v. 74, p. 1367-1377. doi:10.1111/ j.1937-2817.2010.tb01259.x.

Yoder, J.A., Benoit, J.B., LaCagnin, M.J., and Hobbs, H.H., 2011, Increased cave dwelling reduces the ability of cave crickets to resist dehydration: Journal of Comparative Physiology B: Biochemical, Systemic, and Environmental Physiology, v. 181, p. 595-601. doi:10.1007/s00360-011-0555-5. 